\title{
Exposure to Job-related Violence Among Young Female Sex Workers in Urban Slums of Southwest Nigeria
}

Olutoyin Opeyemi lkuteyijo ( $\nabla$ toyin.ikuteyijo@swisstph.ch )

Swiss Tropical and Public Health Institute

Akanni Ibukun Akinyemi

Obafemi Awolowo University lle Ife

Sonja Merten

Swiss Tropical and Public Health Institute

\section{Research Article}

Keywords: Sex workers, young female, violence, slums, phenomenology

Posted Date: February 16th, 2022

DOI: https://doi.org/10.21203/rs.3.rs-1320472/v1

License: @ (i) This work is licensed under a Creative Commons Attribution 4.0 International License. Read Full License 


\section{Abstract}

Background: In Nigeria, many young girls are engaged in commercial sex work as a means of livelihood and support of dependent relatives. Although studies have documented some of the violence related issues among commercial sex workers, the plight of adolescent and young sex workers particularly in urban slums may be different in context and depth.

Objective: This study explored the experiences of violence among young female sex workers and their coping strategies in urban slums in Ibadan and Lagos, Southwest Nigeria.

Design: The study applied an interpretive phenomenological approach through in-depth interviews.

Settings: Young female sex workers ages (15-24 years) who reported having experienced violence were recruited. Data were transcribed using a phenomenological framework analysis. Participants' reports based on life experiences were identified: lived experience "daily brothel life experience"; sources of violence such as law enforcement agents' intermittent raids; violence experience with clients who often demanded sexual acts beyond the agreed scope; and coping strategies employed to mitigate the challenges.

Participants: 12 participants completed the interviews out the 20 initially contacted.

Results: The results showed that the major motivation for engaging in commercial sex work was for economic reasons in order to sustain their livelihood. The risks involved, exposure to violence and other social vices were enormous.

Conclusion: In conclusion, the study raised the need for targeted interventions to mitigate violence against young sex workers. Working with law enforcement officials and health care providers may be the most promising next steps. It should also be made a human rights and public health priority.

\section{Introduction}

Young female sex workers (YFSW) are often exposed to job-related, sexual, physical, economic and psychological abuse and violence perpetrated by clients [1-4]. The United Nations defines violence against women as "any act of gender-based violence that results in, or is likely to result in, physical, sexual, or mental harm or suffering to women, including threats of such acts, coercion or arbitrary deprivation of liberty, whether occurring in public or in private life" [5]. This often results in poor health outcomes in reproductive and mental health [6]. Achieving sustainable development goals (SDGs) i.e. SDG3, which focus on good health and well-being, and SGD5 on gender equality, are relevant to this study. Violence is being experienced among adolescents and young people forced in to sex work [7]. Gender-based violence (GBV) has remained a human rights violation [8], and is associated with negative health outcomes. Female sex workers (FSW) are found in various age groups, a fact rarely considered in the literature. The young age group 15-24 and adults 25-49 have however, different experiences. The age range considered is usually 15-49 years being the reproductive age, but experiences differ according to age groups in terms of health outcomes and other negative experiences $[1,3,9]$. These studies have documented various human violations against sex workers 
(SW) by state and non-state actors. The focus on young women's experiences with sex work over the years has received little attention. [10]

Globally, FSW are among vulnerable groups of women as they experience violence and transmission of infectious diseases. The challenge of an acceptable definition of sex work remains a problem, and remains difficult to describe: consensual exchange of sexual intercourse between adults, for money or other goods, as a livelihood activity [11, 12]. Cheryl describes it as the provision of sexual services for money or goods [13].

Job-related violence among YFSW is diverse in both developed and developing countries. In parts of subSaharan African countries, studies have demonstrated the prevalence of violence among FSW. A study in Kenya [14] found that 79\% reported violence from a client or partner in the last 30 days. In Mombasa $87 \%$ had experienced GBV in their lifetime [15]. In Soweto, South Africa, GBV experience among FSW was attributed to both clients (46.8\%) and police (18.5\%) [16] and sometimes resulted in death [17]. In 5 Southern African countries, 70\% reported experiencing physical and sexual violence in the past 12 months [18]. Violence was found to influence and increased the risk of acquiring HIV [19]. WHO found that eliminating sexual violence against SW had the possibility of reducing $20 \%$ in new HIV infections [20]. Research showed a high number of SW with seropositive HIV status. One estimate from across Global South countries examined the number of SW and proportion with HIV showed: Cameroon 38,582 (36.8\% positive), Burundi 27,546 (22.5\% positive), Rwanda 12,278 (50.8\% positive), Brazil 546,848 (4.9\% positive), and Nigeria 236,146 (24.5\% positive) [19].

In Nigeria today, sex work is regarded as an illegal activity, which makes police- perpetrated violence, client violence, and stigmatization thrive among SW. Nonetheless, Nigerian law does not categorically legalize nor criminalize prostitution. At night, FSW are present in the "red light" districts, hotels, bars and brothels.

YFSW who have experienced diverse forms of violence at the hands of clients, police and others have looked for ways of escape. A study from Nigeria showed how they devised coping mechanisms by setting boundaries, selecting clients and using traditional medicine, charms and drugs to confront those with violent tendencies [21]. Another study showed how they coped with job-related challenges such as the mobility of work within and outside the country [22] to relocate to a more profitable environment. Self-restraint helped in curtailing the extent of violence among clients [23], while others used comforting words to persuade and encourage themselves [24] to cope.

Violent experiences among YFSW have been linked to an increase in HIV infections and other related health problems. Previous studies have established the relationship between violence and its adverse effects on health of the SW, particularly the young women. A systematic review examining the health challenges among FSW showed: $27 \%$ suicidal ideation, $20 \%$ attempts of suicide, $44 \%$ depression and $29 \%$ PostTraumatic Stress Disorder (PTSD) [17]. In addition to deleterious effects on mental health, YFSW were faced with infections ranging from $\operatorname{HIV}[25,26]$ to other genital diseases [27, 28], [15, 29]. YFSW were exposed to unprotected sex with their intimate partners, which increased the risk of HIV infection [30, 31]. The violations have increased unpleasant experiences faced by SW: homicide, physical and sexual violence from clients, 
intimate partners, and law enforcement agents (police), unlawful arrest, demand for money, detention, and discrimination in accessing health care services.

Given the extent, seriousness and consequences of the problems, this study examined job-related violence where research had been conducted on FSW concerning their health, economics/poverty, and violence [29, 32-36]. However, little research had used a phenomenological approach to focus on young women in sex work [10, 21]. While studies have reported on GBV and FSW, less attention had been given to the doubly vulnerable YFSW. There is a need to reduce exposure to violence, discrimination and extortion from police when addressing human rights violations among SW. We identified job-related exposure to violent experiences among YFSW, the health implications, the challenges faced during the course of their activities; and identified their lived experiences and motivation to engage in sex work as well as their coping mechanisms.

\section{Methods}

\section{Setting}

The study was conducted in the major metropolitan cities of Lagos and Ibadan in Nigeria from January to June 2021. Lagos is the biggest metropolitan city with a population projected at 9 million, and Ibadan's population was projected at 3,565,108 making it the third largest metropolitan city. [37]. They are the major cities and have the largest slum areas where sex work strives on a daily basis. Although sex activities are primarily street prostitution, several brothels provided residential accommodations for SW as living space. These brothels are residences for SW where quick sexual services as short as 10 minutes are offered. The participants were YFSW in the Ekotedo area in Ibadan Northeast and Sango and Dopemu in the Agege Local Government Area (LGA), Lagos. These locations were also identified in previous studies as areas where sex worker activities thrived $[9,10]$.

\section{Study design}

The study used interpretive phenomenological analysis (IPA) [38] to explore and interpret the lived experiences of job-related violence among young women engaged in sex work. This ethnographic study was an outgrowth of a larger project to explore various experiences of violence faced by young female adolescents in the slum areas and among young females who were already involved in sex work. IPA was used to explore and draw out individual lived experiences and to describe health challenges, motivation, violence and coping practices and consists of three key elements: phenomenology, hermeneutics, and idiography. The phenomenological component includes a detailed description of how the respondent's world was formed. The hermeneutic aspect interprets and makes intelligible understanding and meaning out of the in-depth dual viewpoints. The idiography helps in understanding the uniqueness of individuals without any biases. These three components complement and help the researcher to pay attention to the participants' detailed experiences [39]. IPA enables the researchers to describe participants' experiences through their life stories [40]. This study used IPA to identify the meaning and interpretation of the 
participants' experiences with violence as well as coping processes. The researcher maintained curiosity and interest in the participants' daily life stories through open interviews, which helped shed more light on their lived experiences.

The focus of the study was on YFSW who had experienced violence in the hands of clients and state actors, lived experience, health challenges and the adopted coping strategies. Qualitative data through in-depth interviews were used, and permission was granted from the brothel managers and the chairlady of the SW in each brothel.

\section{Study population and sampling procedure}

The YFSW offered their services to clients throughout the day, unlike nighttime street prostitutes. Although the Nigeria Criminal Code stated the illegality of brothel ownership [41], these establishments still exist. Street-based commercial sex workers were excluded from this study.

Initially, the method of convenience sampling enlisted 20 participants but only 12 agreed to finish the interviews. The selection was based on young females who had resided in the brothels for at least two consecutive months and who had experienced violence for three months and longer. The interviews lasting approximately 30 minutes were audio taped in the open data kit (ODK) platform to guide against loss of interview information and were sent to the server immediately. The participants were duly informed about the purpose of the study and consent forms were signed although some declined signing because they wanted to protect their identities but gave verbal consent.

\section{Study instruments}

A semi-structured interview guide was utilized with the help of experts from medical sociology, epidemiology and criminology (see Table 1). The participants were asked to share their daily-lived experiences in the brothel: 1) motivations for working in commercial sex work; 2) job-related health challenges; 3 ) exposure to violence; 4) adopted coping strategies; and 5) state and non-state actors' victimization experiences.

Participants were asked to share their stories of different job-related violence since they had begun sex work. Two female research assistants working with local NGOs with Masters' degrees in sociology and demography and experience in qualitative research conducted the interviews with the investigator.

\section{Patient and public involvement}

Patients were not involved in this study. The findings will be disseminated in the form of a policy brief and shared with the brothel management.

Table 1

Guiding questions for the in-depth interview discussions 


\begin{tabular}{|c|c|c|}
\hline Theme & Issue & Guiding question \\
\hline \multirow[t]{8}{*}{$\begin{array}{l}\text { Lived } \\
\text { experience }\end{array}$} & & $\begin{array}{l}\text { (1) How would you describe your activities in a typical } \\
\text { day? }\end{array}$ \\
\hline & & $\begin{array}{l}\text { (a) Probe: for most common activities involved in daily } \\
\text { work }\end{array}$ \\
\hline & & $\begin{array}{l}\text { (b) Probe: could you tell me in what way you } \\
\text { negotiate with your "emotional" partner or clients } \\
\text { regarding protection (condom use)? }\end{array}$ \\
\hline & & $\begin{array}{l}\text { (c) Probe: was there any risks considered while } \\
\text { negotiating? }\end{array}$ \\
\hline & & $\begin{array}{l}\text { (d) Probe: when were clients not ready to use a } \\
\text { condom? }\end{array}$ \\
\hline & $\begin{array}{l}\text { Dynamics of their } \\
\text { relationship with partners or } \\
\text { clients and sexual violence }\end{array}$ & (2) What health problem do women like you face? \\
\hline & & $\begin{array}{l}\text { (a) Probe: for rape, sex, without a condom, painful and } \\
\text { "rough" sex in the vagina and anus }\end{array}$ \\
\hline & & $\begin{array}{l}\text { (b) Probe: for police arrest, drivers' harassments, } \\
\text { physical beating by clients }\end{array}$ \\
\hline \multirow[t]{4}{*}{$\begin{array}{l}\text { Coping } \\
\text { strategy }\end{array}$} & $\begin{array}{l}\text { Coping strategy to avert } \\
\text { harm/violence }\end{array}$ & $\begin{array}{l}\text { (3) How do you practice safe sex to avoid harm from } \\
\text { your clients? }\end{array}$ \\
\hline & & (4) How do you mitigate arrest by police? \\
\hline & & $\begin{array}{l}\text { (a) Probe: for negotiation, payment of unofficial fines, } \\
\text { extending sexual favors. }\end{array}$ \\
\hline & & $\begin{array}{l}\text { (b) Probe: safety nets in case of challenges- financial, } \\
\text { health, criminal, etc.? }\end{array}$ \\
\hline \multirow{6}{*}{$\begin{array}{l}\text { Sexual } \\
\text { gender- } \\
\text { based } \\
\text { violence } \\
\text { (SGBV) }\end{array}$} & & $\begin{array}{l}\text { (5) Have you been assaulted or experienced } \\
\text { stigmatization comments due to your job? }\end{array}$ \\
\hline & & $\begin{array}{l}\text { (a) Probe: for other people known who have had similar } \\
\text { experiences }\end{array}$ \\
\hline & & $\begin{array}{l}\text { (b) Probe: please describe your experiences of being } \\
\text { assaulted or receiving negative or stigmatizing } \\
\text { comments (narrate specific experiences) }\end{array}$ \\
\hline & & $\begin{array}{l}\text { (c) Probe: What was your response? How did you } \\
\text { handle these? }\end{array}$ \\
\hline & & $\begin{array}{l}\text { (d) Probe: what type of services did you seek after the } \\
\text { assault? }\end{array}$ \\
\hline & $\begin{array}{l}\text { Places and context in which } \\
\text { violence occurs }\end{array}$ & $\begin{array}{l}\text { (6) Could you tell me what usually causes disagreement } \\
\text { or violence between you and your clients? }\end{array}$ \\
\hline
\end{tabular}


(a) Probe: provide instances (narrative)

(7) When you experience violence/harm from your clients, where does it usually happen?

(a) Probe: in the hotel room, in the car, in the bar?

Influence of societal

pressure

(8) Could you tell me how people relate with you and describe your relationship with other people?

(9) Are there times when people abuse you (verbally, discriminate or harm) because of work related identity?

(10) Please could you share your or other experiences of stigmatization with services like health care providers or the police?

\section{Analytical process}

The analysis of the data was completed according to research objectives. The interviews were collected using open data kits (ODK) and were transcribed verbatim. The Atlas ti version 8, a computer-assisted qualitative data analysis software (CAQDAS) was used. The in-depth reading of the transcripts and iterations, codes and themes were developed for inductive analysis. Framework analysis [42] was used to extract job-related violence experienced by YFSW. The steps recommended by Gale et al. were followed: 1) transcription; 2) familiarization with the interview; 3) coding; 4) developing a framework; 5) applying the framework; 6) charting data into a framework matrix; and 7) interpreting the data [42]. Reflexivity was guaranteed with additional field notes to guide the analysis and included observation, informal discussions with respondents and reflections after each interview. Reporting was guided by Consolidated Criteria for Reporting Qualitative Research (COREQ-32) [43]. A code tree was developed showing thematic analysis of the data (see figure 1).

\section{Findings}

\section{Socio-demographic characteristics of the respondents}

The age range of the girls was 15-24 with a majority above age 20 (60\%) while the rest were between ages 15-19. The average educational level attained was primary school. Two of the respondents started in the sex work less than 3 months before the survey, while the rest had been in the business for 2 or 3 years. All the participants claimed they solely engaged in vaginal sex with their clients. They all claimed using condoms during the intercourse; either female or male condoms were appropriate.

\section{Lived experience}


The study findings revealed that young girls in the brothels were not residents of those communities where the brothels (i.e. drinking joints) were situated. A shelter was attached where the young women rented an apartment and brought their clients for daily sexual activities. They explained their activities, called "hustles" as they were involved with at least three or four men, and a maximum of 20 per day, with price differences.

"... when I wake up, I will take my shower, after my shower, I will eat, relax, and maybe sleep for like some hours. If I do not feel like sleeping, I will go to the bar. After then during the evening I will dress up and hustle for customers." (YFSW Ibadan)

When the young women achieved their maximum number of clients on a daily basis, this was a high point for them.

"On a normal day, good day, I can have up to 20 or 30 customers. Sometimes, I will not have up to ten, but I will get a lot of money. Okay let me say sometimes few people like 5 or 2 would enter my room, I would get a lot of money as well." (YFSW Ibadan)

They indicated their time limits for sexual activities with each client in order to achieve their daily target number and expected amount of money.

"...Ehnn some time I get o, I just get customers, I can get like twenty in a day, and if I can cope I will accept them all. Highest is 30 minutes! Some spend more than 30 minutes, maybe at the end of the day; it's mainly people that do stay long that spend that 30 minutes, some 5 minutes. It depends, all body systems are not the same. "(YFSW Lagos)

\section{Motivation to engage in commercial sex work (CSW)}

The YFSW commented that money was their motivation due to the high level of unemployment. Sex work was one of the available job options for young people and a means to meet their needs i.e. clothing, food and housing.

"... With this kind of place we are, you know what we do here now. We hustle to find money because is money that bring us here. Not that we are in our fathers house or our aunties' house. Therefore, we came here to find money. So we don't have choice (YFSW Ibadan)."

\section{Exposure to violence}

The violence experienced included physical, sexual, verbal and emotional abuses. Gender violence has been highly prevalent among women in Nigeria and Africa. YFSW experienced violence due to their age and suffered in the hands of clients and police officers. Some explained that clients would introduce diabolic activities or ideas during sexual intercourse; an example being that some clients would request to take away the discharge (semen) and offered extra money for such requests. It is important to define diabolic in the context of this study as "vile, cruel, worthy of an evil spirit, malicious, or immoral. Also, another definition is 
"having or showing a desire to cause someone pain for sheer enjoyment". These two definitions are applicable to the experiences of young females in the sex work.

"Yes sometimes customers usually fight us. When they pay for foreplay and enter to start asking for other things. In the course of collecting the money back, it can cause violence" (YFSW Lagos).

Concerns were shared as to how the clients took advantage of them during sexual intercourse due to their age: forced sex, rough sex, amount of time, and condoms bursting during intercourse.

".... when they go inside and we started, they will just change, that is it. For example, if they are not supposed to kiss, in the middle of the act, you just see them kissing you forcefully even if you push them; they force your face down". (YFSW Lagos)

"..Some of them while having sex with you, will sometimes burst the condom and if that happens with me that is the end of the business because I cannot take another condom for the person and I will ask him to go. So this usually causes fight." (YFSW Lagos)

The participants explained that many clients were drunk or on drugs, which delayed their release during sexual intercourse. The challenge of defaulting the agreement was usually from the client's side, which mostly resulted in violence.

"Sometimes they will say, you did not allow them to "ejaculate", as in release, because they have taken some stimulants or you didn't allow them to touch your breast. One has hit me once and said 'how can I be paying you and you did not allow me to touch your breast' and that was not part of our agreement 0 . You know some customers are very stubborn, you will agree on something outside, they will demand for something else when you both are alone inside" (YFSW Lagos \& Ibadan).

Clients often demanded maximum sexual satisfaction, which invariably amounted to more time. If the request was declined, it often led to violence. At the intervention of the brothel manager, these issues were resolved without violence. Attainment of sexual satisfaction "ejaculation" mostly caused violence from clients and could only be resolved when clients were ready to pay a premium for more time to enjoy maximum satisfaction leading to sexual climax.

\section{Job-related challenges}

Health related issues, which could be in the form of physical injury, vaginal infection, infertility, fear, and forms of diabolic incidents were problematic.

"One day after intercourse, the client wanted to go away with the sperm in used condom but I objected. He told me he would give me more money, I insisted. This led to him being violent, but I insisted and he left without paying me." (YFSW Ibadan)

Long duration of sex from the clients raised many concerns and this had been a reoccurring challenge. 
".. The challenge is that some of these men will go outside and take drugs, and then they will come here and pay you for short time. Unfortunately, they will not be able to release on time, this will cause harassment, and insult and they want you to return their money." (YFSW Ibadan)

Commercial sex workers faced various risks but YFSW faced more due to their age. Some clients demanded to go "extra miles" with them like sucking their breasts. There were cases where other clients wanted them to participate as an accomplice in their criminal activities.

"...some of us usually think any clients want to transfer sickness. Sometimes, they will come with charm and say they want to suck your breast or have sex without any protection ("skin to skin"). Then when you oppose, it will cause negative reaction." (YFSW Ibadan)

"....there was a time, a guy came to hide cocaine in my room but I refused. If anything happens, it will tarnish my image, as my family do not know I engage in this type of job." (YFSW Ibadan)

\section{Abuses by state and non-state actors}

\section{State actors' abuses}

Some participants suffered abuses from state actors like police officers. Police officers often demanded bribes. If there were no payments, the YFSW would be arrested and taken to the police station. Hence, most had devised a means of making money available for the police whenever the brothels were raided.

".... (Laughs), in this place like that, we face a lot of problems, police issues. Yes, about the police issue, if they come, you know this kind of job (laughs), it is free food for them." (YFSW Lagos)

"...They do come here, but they do not arrest anyone because we pay them on a monthly basis. Each girl here contributes 3500 per month for police". (YFSW Ibadan)

\section{Abuses from non-state actors}

YFSW experienced abuse from people around them. The name "Ashewo" is a household name for someone engaged in sex work. They were faced with clients' harassments and in some occasions, clients' partners coming to the brothel to confront them.

"...they will say things like "ashewo" mean prostitute, don't go and look for work to do, instead of just using yourselves to make money" and they don't give us respect like other girls that are not in the street even the customers". (YFSW Lagos)

Clients made unpleasant gestures and when YFSW complained, they were adamant and never ready to apologize appropriately. 
"....the customers, if they do something you do not like and you tell them, if those that are responsible, they will understand and apologize, but some of them those ones that are not responsible, it will lead to para (fight) you understand. (YFSW Lagos)

\section{Coping mechanisms}

The use of comforting words, exercising restraints, and being 'vigilant' (i.e. they treated all clients as suspects who wanted more than sex) were devised as a means to cope with job- related violent encounters in order to survive.

"...If a client hires me till day break (overnight), I don't usually sleep because of fear of whatever dangerous thing might happen" (YFSW Lagos)

"Yes they use condom but I will use my hand to put the condom and after which I don't allow them to touch it again because of the fear of some that use "juju power" diabolic power and use girls for rituals"(YFSW Lagos/Ibadan)

YFSW were aware of health implications surrounding the sex work and in making conscious efforts not to affect their future health.

"... I can't allow them to do rough sex with me, and if they force me I will not open my leg very well I will just open it small. The reason is if you open leg too much it can affect our womb" (YFSW Lagos)

Due to their youth and fear of reactions to their client's violence, another coping strategy was remaining compliant in the form of "fear". Some respondents declared they would do anything to satisfy a demand to avoid trouble or any violent act.

"...If you bring customer inside, if you do not satisfy him well he will curse you, talk to you anyhow nonsense. If you curse him also, he will start fighting you. Therefore, as for me, I do not like that. If I take them inside, I will satisfy them well because as I am, I do not look for trouble. It is not because of trouble that bring me here." (YFSW Ibadan)

\section{Health awareness and challenges}

A common health challenge was bleeding during sexual intercourse and this caused them need to recover from work.

"...HIV, sexually transmitted disease, I have never been raped by a client before because he won't even come in from outside if we don't agree, but I have situations when clients are rough and caused me to bleed" (YFSW Lagos)

Over the years YFSW have advanced by protecting themselves medically. They go to clinics for treatment for any traces of infections 
"... When I need to receive treatment for anything, I go to private hospitals, they are not rude to you for any reason because it is their work and you pay them for it. So, what I do is not their business". (YFSW Lagos)

The use of contraceptives was very important and all reported they used both female and male condoms during sexual intercourse. The only time they did not use contraceptives was when they had intercourse with their boyfriends; about half of the participants reported that their boyfriends were aware of their work.

"I do use protection $100 \%$ and I use to tell them (customers)". "....he will go out now; it's only my boyfriend that I can have sex with without protection". (YFSW Lagos)

Despite protection, few of the YFSW admitted they experienced "flesh to flesh" (unprotected) sexual intercourse with clients who were ready to pay a premium amount of money.

"...okay, for me, sometimes if I see that you give me a lot of money, I have two things to do. Either I use a female condom or I use cotton wool. If you do not release inside me, then you will release on that cotton wool and I will remove it out. If you give me a lot of money, if I don't have that female condom, that is what I do. But if I have, I normally use that female condom." (YFSW Ibadan)

With this agreement, they endeavored to protect themselves without the knowledge of their clients.

Another health challenge was that of a diabolical act from the client.

"Sometimes, they will bring charm for you that they want to suck your breast, or request for skin to skin 'sex without condom'. Then when you refuse, the clients start acting negative." (YFSW Ibadan)

Injury during sex work activities was cited. Condoms burst during intercourse with clients, while others had experienced excessive bleeding which could make them need to recover for some days.

"..Frequent penetration to the vaginal causes womb to shift from its original position. In addition, because we use bathroom and toilet together, one can contact infection." (YFSW Lagos)

\section{Discussion}

Our findings indicated that female adolescents and young girls were willingly involved in sex work. Clients were the major perpetrators of violence which went beyond physical, sexual, and emotional to diabolical means. The YFSW experienced violence in the hands of clients, encountered economic frustration, and experienced abuses from both state and non-state actors. This is similar to experiences of their counterparts in Ghana [44]. The narratives of lived experience of YFSW on a daily basis in the brothels [29] relied on the hope of getting paid by customers to cover their daily needs. The rate of customer flow depended on the profit for the day, and mostly the sexual activities were a short-term experience to allow for more clients. The major expression used to get a client for sexual activities was "I want to hustle". Commissions were paid to the group leader "chair lady" and the brothel owner on weekly basis. The major motivation expressed by YFSW was receiving money on a daily basis, which kept them in the business. 
In consonance with previous studies $[1-3,45,46]$, clients were one of the major perpetrators of violence among FSW and YFSW suffered more. Due to their age, greater exploitations were encountered: forced sex, free sex, unprotected sex, physical violence, longer time beyond the bargained time for sexual satisfaction, and diabolic requests. However, this study corroborates previous studies by showing that YFSW are at greater risk of job-related violence, sexually transmitted infections, HIV and other reproductive health outcomes $[44,47,48]$.

Health challenges were one of the major concerns as implications of violence. The YFSW understood the health implications of their business and made conscious efforts of health protection by using condoms. Although a majority agreed that they used condoms for all customers, very few stated that they occasionally had sex with clients without condoms, which corroborates with previous studies [31, 49]. Excessive bleeding, genital infections, sexually transmitted diseases, and shifting of the womb, which could potentially cause infertility in the future, were concerns being consistent with previous studies $[15,27,28]$.

YFSW suffered abuses in the hands of state (police and health workers) and non-state (clients and other people) actors. Police arrested them for no apparent reason. Demand for money as an entitlement was a major concern, which was in conjunction with previous studies $[34,50]$. However, YFSW had devised several means of coping: being vigilant, setting boundaries, self-restraints, expressing comforting words to the clients and relocating from a particular location [21-24]. These coping mechanisms are in tandem with findings from previous research. The participants demonstrated coping by satisfying the clients' sexual urges to avoid any violent attacks. Others tried to cope by being vigilant of any clients that approached them for unusual sexual activities.

\section{Strengths and limitations}

One key strength of the study was that the data collected were strictly from young females in the commercial sex work industry who resided in the slums. Additionally, they were residents in brothels and worked full time in sex work with varying experiences.

This study had some limitations. The number of participants were few due to the age range considered and they were not too confident in sharing their experiences despite the assurance of anonymity and confidentiality. Second, since the present study consisted of self-reporting interviews, questions on personal healthcare received passive responses from almost all due to nature of their jobs. Getting them to respond to the interviews took time, until we assured them that we would move quickly with our discussion. Fourth, most of the respondents were migrants; they moved to locations where there were no families nor relations to recognize or apprehend them. Nevertheless, the interviews have provided us with vital information for this study.

These data made it clear that young people suffer much violence in the hands of clients and police, and stigmatization in the community. Including different categories of adolescents in the overall study gave room to explore the importance the impact of violence affects those in sex work. Female adolescent SW must be part of inclusive interventions, as this group will later in life transit into the society by either 
marriage or childbirth. Law enforcement agencies should responsibly consider this group especially in terms of building National Gender Policy.

\section{Conclusion}

The study showed that exposure to violence is not only peculiar to older groups of FSW but that the younger ones were more vulnerable. There is a need for enlightenment and social orientation by government and non-governmental agencies, making violence against YFSW a public health and human rights priority on local and national policy agendas. The agenda should include work environment conditions, gender and economic inequities, stigma and security of lives. Interventions like "Naija-girls" in Lagos state targeting adolescents and young peoples' sexual and reproductive health should focus on YFSW, as there is potential to influence their decisions. Health care providers must be more sensitive to young SW and create enabling environments. Sensitization of the police and anti-violence activities among clients as well as a broader discussion on how to better protect young women by the state should be prioritized. Female police should check on brothels and ensure the welfare and health safety of this group. Monitoring and evaluation of this program will make a structural contribution and provide guidance on how best to meet the demands of highly vulnerable young females in sex work. Findings from previous studies from Nigeria indicated less focus and ignored adolescents and young females involved in sex work, which will invariably increase their vulnerability. The study therefore encourages that more research be conducted on violence experienced among adolescents and young females who are engaged in sex work activities and on their health implications, future aspirations, and their fears.

\section{Declarations}

\section{Consent to participate}

All the participants give their consent by reading and signing the consent form and agreed verbally before conducting the interview.

\section{Consent for publication}

Not applicable

\section{Availability of data and materials}

The dataset presented in this article are not publicly available, because it contains information that could compromise the privacy of the interviewees and a breach of agreement. Request to access the dataset can be directed to the corresponding author.

\section{Competing interest}


The authors declare they have no competing interest

\section{Funding}

This study was part of the larger study on adolescent violence experience in the slums area in Nigeria funded by BOTNAR Foundation and the European Union's Horizon 2020 research and innovation program under the Marie Sklodowska-Curie grant agreement No. 801076, through the SSPH+ Global PhD Fellowship in Public Health Sciences (GlobalP3HS) of the Swiss School of Public Health. The sponsors had no role in the study design, data collection and analysis, decision to publish, or preparation of the manuscript.

\section{Authors' contributions}

OOI collected, analyzed and interpreted the interview transcripts and wrote the manuscript. AlA supervised the data collection and reviewed the manuscript. SM supervised the interpretation of data and critically reviewed the manuscript. All authors read and approved the final manuscript.

\section{Acknowledgments}

We thank the manager and the chair-lady of the brothels for giving us the opportunity to talk to the young female sex workers. We also thank the participants for their insight into their personal experiences. We thank Damilola Amire and Oluwakemi Olateju who supported in data collection. We also thank Karen Maigetter for taking time to edit the manuscript.

\section{Ethics approval and consent to participate}

Approval for the study was embedded in a larger study from Ethics Committee Northwest and Central Switzerland (ID Number: AO-2020-00028) and University of Ibadan Research Ethics Committee (ID: $\mathrm{UI} / \mathrm{EC} / 20 / 0513)$. It was conducted in accordance with the Declaration of Helsinki. Permission was granted by Ibadan Northeast LGA and from Agege and Orile-agege LGA Lagos. Written consent was obtained from participants as part of the approved ethical guidance. Participants agreed to participate in the study and could stop the interview at any time. Confidentiality was assured; all the given names were pseudonyms to protect the participants.

\section{Author details}

${ }^{1}$ Department of Epidemiology and Public Health, Swiss Tropical and Public Health Institute, Basel, Switzerland, ${ }^{2}$ University of Basel, Basel Switzerland, ${ }^{3}$ Department of Demography and Social Statistics Obafemi Awolowo University lle Ife, Nigeria 


\section{References}

1. Semple, S.J., et al., Prevalence and Correlates of Client-Perpetrated Violence against Female Sex Workers in 13 Mexican Cities. PLoS One, 2015. 10(11): p. e0143317.

2. Thomas, A., A critical evaluation of commercial sexual exploitation among women in Kogi state, Nigeria. International Journal of Management, Social Sciences, Peace and Conflict Studies, 2020. 3(20): p. 24-30.

3. Lieber, M. and H. Le Bail, Aren't Sex Workers Women? Ladies, Sex Workers and the Contrasting Definitions of Safety and Violence. ACME: An International Journal for Critical Geographies, 2021. 20(3): p. 241-256.

4. Popoola, B.I., Occupational hazards and coping strategies of sex workers in southwestern Nigeria. Health care for women international, 2013. 34(2): p. 139-149.

5. United Nations, Declaration on the elimination of violence against women. New York: UN, 1993.

6. Sherwood, J.A., et al., Sexual violence against female sex workers in The Gambia: a cross-sectional examination of the associations between victimization and reproductive, sexual and mental health. BMC Public Health, 2015. 15: p. 270.

7. Franchino-Olsen, H., Vulnerabilities relevant for commercial sexual exploitation of children/domestic minor sex trafficking: A systematic review of risk factors. Trauma, Violence, \& Abuse, 2021. 22(1): p. 99111.

8. United Nations, Declaration on the Elimination of Violence against Women Proclaimed by General Assembly resolution, in 48/104, United Nations: Human Rights Office of the High Commissioner, Editor. 1993.

9. Aborisade, R.A., O.A. Adeleke, and T.A. Oshileye, Victims of the 'victimless crimes': the narratives of residents of red-light districts in Ibadan, Nigeria. Gender and Behaviour, 2018. 16(1): p. 10874-10888.

10. Abideen Aderinto, A. and E. Ima Samuel, Adolescents at risk: A qualitative study of adolescent sex workers in Ibadan. South African Review of Sociology, 2008. 39(1): p. 38-50.

11. Standing, H., AIDS: conceptual and methodological issues in researching sexual behaviour in subSaharan Africa. Social Science \& Medicine, 1992. 34(5): p. 475-483.

12. UNAIDS and UNDP, Criminalization of HIV transmission: policy brief. http://data.unaids.org/pub/basedocument/2008/20080731_jc1513_policy_criminalization_en.pdf2008.

13. Overs, C., Sex workers: part of the solution. An analysis of HIV prevention programming to prevent HIV transmission during commercial sex in developing countries. Unpublished report, 2002.

14. Pack, A.P., et al., Intimate partner violence against female sex workers in Mombasa, Kenya. Culture, health \& sexuality, 2014. 16(3): p. 217-230.

15. Roberts, S.T., et al., Patterns of gender-based violence and associations with mental health and HIV risk behavior among female sex workers in Mombasa, Kenya: a latent class analysis. AIDS and behavior, 2018. 22(10): p. 3273-3286.

16. Coetzee, J., G.E. Gray, and R. Jewkes, Prevalence and patterns of victimization and polyvictimization among female sex workers in Soweto, a South African township: a cross-sectional, respondent-driven 
sampling study. Glob Health Action, 2017. 10(1): p. 1403815.

17. Millan-Alanis, J.M., et al., Prevalence of suicidality, depression, post-traumatic stress disorder, and anxiety among female sex workers: a systematic review and meta-analysis. Archives of women's mental health, 2021: p. 1-13.

18. Project, A.N.H.O., Sex work and violence in Southern Africa: a participatoryresearch in Botswana, Mozambique, Namibia, South Africa and Zimbabwe. 2018 a.

19. UNAIDS, Global AIDS Response Progress Reporting. Constrution of Core Indicators for monitoring the 2011 United nations Political Declaration on HIV and AIDS.https://www.unaids.org/sites/default/files/media_asset/GARPR_2014_guidelines_en_0.pdf. 2014.

20. World Health Oganization (WHO), Sex workers. Global HIV, Hepatitis and STIS Programmes.https://www.who.int/teams/global-hiv-hepatitis-and-stis-programmes/populations/sexworkers. 2021.

21. Otutubikey Izugbara, C., 'Ashawo suppose shine her eyes': Female sex workers and sex work risks in Nigeria. Health, Risk \& Society, 2005. 7(2): p. 141-159.

22. Finger, S., Sex-work and Mobility as a Coping Strategy for Marginalized Hungarian Roma Women. ACME: An International Journal for Critical Geographies, 2016. 15(1): p. 104-128.

23. Puente-Martínez, A., et al., "Mouth Wide Shut": Strategies of Female Sex Workers for Coping With Intimate Partner Violence. Journal of interpersonal violence, 2019. 34(16): p. 3414-3437.

24. Arrey-Mbi, S.B., PROSTITUTION IN BAMENDA: A TRADE AND A COPING STRATEGY FOR SOME WOMEN. Asian Journal of Social Sciences \& Humanities Vol, 2020. 9: p. 2.

25. Muñoz, J., A. Adedimeji, and O. Alawode, 'They bring AIDS to us and say we give it to them': Sociostructural context of female sex workers' vulnerability to HIV infection in Ibadan Nigeria. SAHARA-J: Journal of Social Aspects of HIV/AIDS, 2010. 7(2).

26. Shannon, K., et al., HIV infection among female sex workers in concentrated and high prevalence epidemics: why a structural determinants framework is needed. Current Opinion in HIV and AIDS, 2014. 9(2): p. 174-182.

27. Fayemiwo, S., et al., Genital ulcer diseases among HIV_infected female commercial sex workers in Ibadan, Nigeria. 2011.

28. Forbi, J., et al., High prevalence of hepatitis $B$ virus among female sex workers in Nigeria. Revista do Instituto de Medicina Tropical de São Paulo, 2008. 50: p. 219-221.

29. Nelson, E.E., The lived experience of violence and health-related risks among street sex workers in Uyo, Nigeria. Cult Health Sex, 2020. 22(9): p. 1018-1031.

30. Blanchard, A.K., et al., A community-based qualitative study on the experience and understandings of intimate partner violence and HIV vulnerability from the perspectives of female sex workers and male intimate partners in North Karnataka state, India. BMC Womens Health, 2018. 18(1): p. 66.

31. Beattie, T.S., et al., Reducing violence and increasing condom use in the intimate partnerships of female sex workers: study protocol for Samvedana Plus, a cluster randomised controlled trial in Karnataka state, south India. BMC public health, 2016. 16(1): p. 1-11. 
32. Aborisade, R. and J. Fayemi, Violence and vulnerability: Exploring the exposure of street-based sex workers in Ibadan, Nigeria. Ago-Iwoye Journal of Social and Behavioural Sciences, 2015. 4(1): p. 134151.

33. Adelekan, A.L., et al., Sexual Practices of Female Sex Workers in Ibadan, Nigeria. International STD Research \& Reviews, 2017: p. 1-10.

34. Aborisade, R.A., Police abuse of sex workers in Nigeria: evidence from a qualitative study. Police practice and research, 2019. 20(4): p. 405-419.

35. Fawole, O.I. and A.T. Dagunduro, Prevalence and correlates of violence against female sex workers in Abuja, Nigeria. African health sciences, 2014. 14(2): p. 299-313.

36. Salihu, H.A. and O.A. Fawole, Police Crackdowns, Human Rights Abuses, and Sex Work Industry in Nigeria: Evidence From an Empirical Investigation. International Criminal Justice Review, 2021. 31(1): p. 40-58.

37. Worldometer, Elaboration of data by United Nations, Department of Economic and Social Affairs, Population Division. World Population Prospects: The 2019 Revision.https://wWw.worldometers.info/world-population/nigeria-population/. 2021.

38. Tuffour, I., A critical overview of interpretative phenomenological analysis: A contemporary qualitative research approach. Journal of Healthcare Communications, 2017. 2(4): p. 52.

39. Lee, K., A study on the significance and the application of interpretative phenomenological analysis as a qualitative research. J. Qual. Res, 2013. 14: p. 132-144.

40. Smith, J.A., Evaluating the contribution of interpretative phenomenological analysis: $A$ reply to the commentaries and further development of criteria. Health psychology review, 2011. 5(1): p. 55-61.

41. Nigeria Criminal Code, Criminal Code Act-Laws of Nigeria. Section 225b https://lawsofnigeria.placng.org/laws/C38.pdf. 1990.

42. Gale, N.K., et al., Using the framework method for the analysis of qualitative data in multi-disciplinary health research. BMC medical research methodology, 2013. 13(1): p. 1-8.

43. Tong, A., P. Sainsbury, and J. Craig, Consolidated criteria for reporting qualitative research (COREQ): a 32-item checklist for interviews and focus groups. International journal for quality in health care, 2007. 19(6): p. 349-357.

44. Onyango, M.A., et al., "It's all about making a life": poverty, HIV, violence, and other vulnerabilities faced by young female sex workers in Kumasi, Ghana. JAIDS Journal of Acquired Immune Deficiency Syndromes, 2015. 68: p. S131-S137.

45. Peitzmeier, S.M., et al., Polyvictimization Among Russian Sex Workers: Intimate Partner, Police, and Pimp Violence Cluster With Client Violence. J Interpers Violence, 2019: p. 886260519839431.

46. Armstrong, L., Stigma, decriminalisation, and violence against street-based sex workers: Changing the narrative. Sexualities, 2019. 22(7-8): p. 1288-1308.

47. Marshall, B.D. and E. Wood, Sex work and sex exchange among street children: an urgent need for a global response. J Adolesc Health, 2009. 44(3): p. 201-2. 
48. Asamoah-Adu, C., et al., HIV infection among sex workers in Accra: need to target new recruits entering the trade. J Acquir Immune Defic Syndr, 2001. 28(4): p. 358-66.

49. McCann, J., G. Crawford, and J. Hallett, Sex Worker Health Outcomes in High-Income Countries of Varied Regulatory Environments: A Systematic Review. International journal of environmental research and public health, 2021. 18(8): p. 3956.

50. Footer, K.H.A., et al., Police-Related Correlates of Client-Perpetrated Violence Among Female Sex Workers in Baltimore City, Maryland. Am J Public Health, 2019. 109(2): p. 289-295.

\section{Figures}

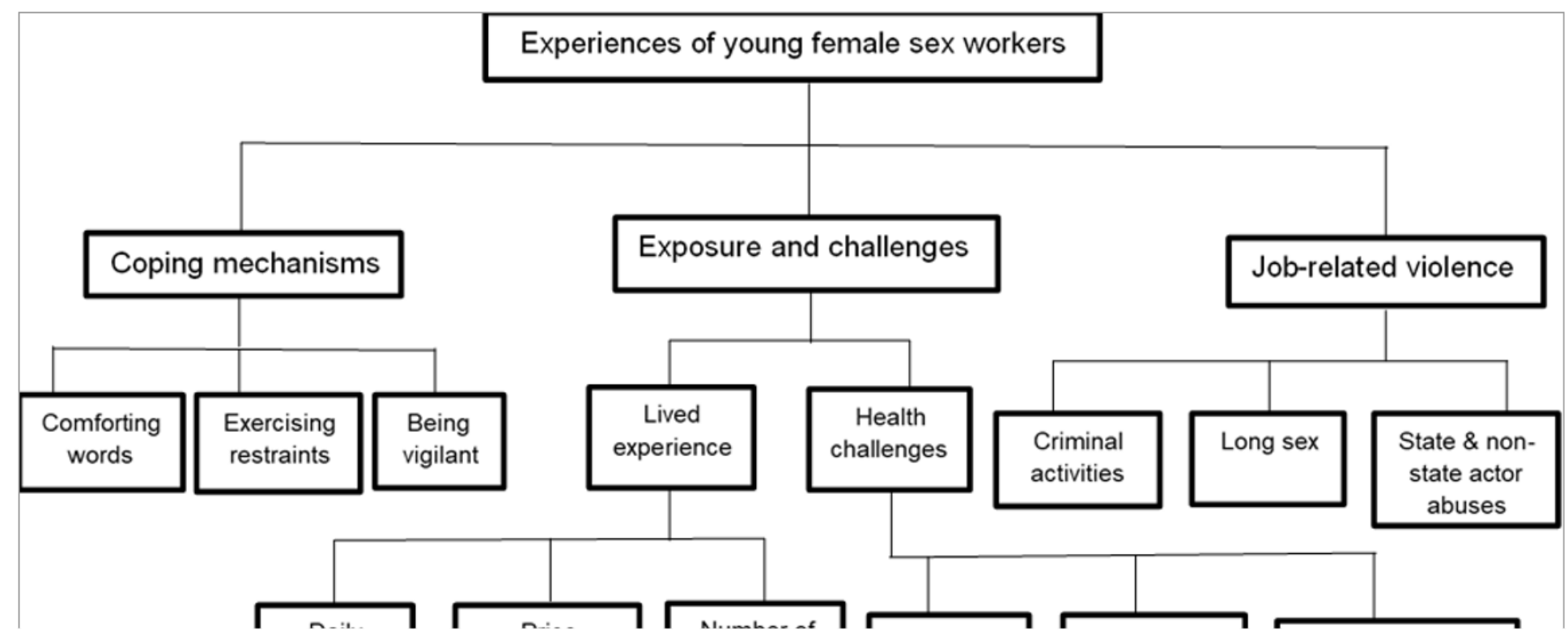

Figure 1

Coding tree for thematic analysis. 